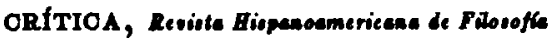

Vol. XX, No. 89 (agouto 1988): 4s-67

\title{
WHAT SHOULD A THEORY OF MEANING DO?*
}

Mark Platts

Instituto de Investigaciones Filosóficas, UNAM

Nearly fifty years ago W. V. O. Quine fired the first shots in what was to prove a sustained engagement with then dominant dogmas as to the nature of meaning. Many fronts were involved in that engagement and much philosophical shot has since been fired; but I think it reasonable to say that the consensus largely to have emerged is that Quine was far more right than wrong in his original scepticisms. Yet that view sits alongside a continuing concern with what is called 'the theory of meaning'. This paper is a tentative attempt at examining some aspects of that continuing concern from a viewpoint that I would like to think of as neo-Quinean in character.

1. Two apparently clear, and apparently clearly distinct,

- Some of the anxieties occasioning this paper were hinted at in my editor's introduction to Reference, Truth and Reality (London, 1980) as a way of registering the disquiet I had come to feel with some points of my Ways of Meaning (London, 1979). The present paper has I think profited from helpfully critical responses to earlier versions read at U.C.L.A. (19.80) and the Universities of Bradford (1981) and Copenhagen (1982). In the Summer of 1980 Donald Davidson subjected one such version to extensive examination in a research seminar in the Universidad Nacional Autónoma de México. I learnt far more from his remarks there than he might think is suggested by this latest version. My general indebtedness to his writings, as to those of John McDowell, must be clear despite the tentative disagreements with them revealed by this paper. 
enterprises have been taken to fall under the rubric 'construction of a theory of meaning'. One is that of devising a theory of meaning for some particular language, a theory serving "to give the meaning" of the expressions of that language. The other is that of developing a philosophical theory of meaning, a theory specifying the form which theories of the first type should take. The philosophical theory is a theory of theories of meaning for particular languages.

However clear and obvious that might now seem, the relations between those enterprises and the nature of each are all matters of great obscurity. I shall explore some of the complexities in this area through an examination of the only currently serious candidate for the second, philosophical, enterprise: the only candidate whose basic structure has been sufficiently articulated, and whose consequences, including the problematic, have been sufficiently explored. I refer, of course, to the truth-conditions conception of meaning.

As my representative truth-conditions theorist I choose John McDowell, while not wanting to deny his indebtedness to the work of others. ${ }^{1} \mathrm{He}$ tells us: "If there can be such a thing as a theory of meaning for any language, meaning cannot be anything but what any such theory is a theory of" (TC, p. 42). He thus thinks that "a clear and convincing description of the shape which a theory of meaning for a language should take, not itself uncritically employing the notion of meaning, ought to remove all perplexity about the nature of meaning in general" (TC, p. 42). So the construction of

1 Principally by reference to his "Truth Conditions, Bivalence, and Verificationism" (hereafter 'TC'), in Gareth Evans and John McDowell (eds.), Truth and Meaning (Oxford, 1976), pp. 42-66. I later draw upon McDowell's "On the Sense and Reference of a Proper Name" (hereafter 'PN'), Mind, LXXXVI (1977), pp. 159-85, and upon his introduction, with Gareth Evans, to Truth and Meaning (hereafter 'EI'). 
what I have just called a philosophical theory of meaning ought "to remove all perplexity about", and hence neatly put paid to a scepticism as to there being any such thing as, "the nature of meaning in general".

But an ambiguity lurks in McDowell's initial claim about the theoretical character of the notion of meaning. On one reading, the claim amounts to this: while we have some pre-theoretical grasp upon the relevant concept of meaning, still we might go on to discover, through reflection upon the general, philosophical theory of meaning, quite what that concept is upon which we are presumed to have some pre-theoretical grasp. ${ }^{2}$ Hence the reasonableness of our employing, albeit not in an 'uncritical' manner, that partially grasped concept in the very process of describing "the shape which a theory of meaning for a language should take". What could the posited pre-theoretical grasp be? The obvious suggestion would be this: our pre-theoretical understanding of what is purportedly done by elements of theories of meaning for particular languages-our grasp, for example, of what is said by some utterance which purports to "give the meaning" of some English expression. The pre-theoretical conception of meaning there revealed is what is to be refined through the attempt to devise a philosophical theory of meaning.

But a stronger reading of McDowell's initial claim is also available. On this reading, any pre-theoretical grasp upon the relevant notion of meaning is denied. The relevant notion is a technical, purely theoretical one

2 Thus we might be led, for example, to appreciate objectionable obscurities within the idea that the deliverances of a theory of meaning should take the form of direct statements of the form 'sentence s means that $p^{\prime}$. Cp. PN, p. 161, and my introduction to Reference, Truth and Reality, pp. 7-8. But if our intuitions about "giving the meaning" can be revised-not just augmented-in this way, just what control do they provide? 
of which the ordinary speaker need have no conception. Our grasp, as theorists, of that notion is determined by, and exhausted by, its being the subject-matter of our philosophical theory. The pertinent concept of meaning therefore cannot be employed, not even in a 'critical' manner, in elucidating "the shape which a theory of meaning for a language should take" since such an employment would presume us to have some understanding of that concept outside of the description of that shape, which understanding aids the elucidatory aim. As competent native speakers, for example, either we have, or need have, no grasp upon what is said by some utterance purporting "to give the meaning" of some expression in our native language or, perhaps more plausibly, such grasp as we have upon that has no bearing upon the concept of meaning which a philosophical theory of meaning aims to crystallise.

Were McDowell's initial claim true upon the second, stronger reading, a puzzle would immediately arise. The stated aim is to illuminate 'the nature of meaning in general' through a consideration of the general form to be taken by theories of meaning for particular languages. Yet we would have, apparently, no reason for viewing that philosophical theory as one of meaning since we would have, apparently, no reason for holding the particular theories whose general form was described by that philosophical theory to be theories of meaning for the particular languages under study. $E x$ hypothesi, for example, reference to our native grasp upon what was being said by deliverances of such a particular theory for our native language would not license the invocation of a relevant notion of meaning in elucidatory description of the subject-matter of the philosophical theory: for either we should be deemed to have no such grasp or it would have been discovered 
that such grasp as we have had nothing to do with that subject-matter.

To remain agnostic at this stage, I shall refer to McDowell's truth-conditions theory as one of sense (as he himself does at various points). The entitlement of that theory to. being held to be a theory of meaning can then later be considered.

2. McDowell argues for the identification of a theory of sense with a theory of truth-conditions by considering the role to be played by a theory of sense within an overall theory of linguistic behaviour.

A theory of linguistic behaviour has the following aim: starting from observation of some speaker's emission of noise, the theory should enable us to redescribe that event so as to see it as an intelligible piece of linguistic behaviour. To realize that aim, the theory will need at least the following structure. One component should enable us to identify tentatively (at least some) emissions of noise as intentional verbal behaviour. A second will tentatively identify the modes of utterances, the most general types of speech-act being performed: asserting, questioning, commanding, etc. Neither of these first two components will bear much resemblance to anything which could with precision be called a theory: the recording of a certain amount of wise, folkloric perception is all that could reasonably be hoped for here. The third component will be more evidently theoretical: this will identify the grammatical moods of sentences uttered: indicative, imperative, interrogative, etc. The fourth component of the theory of linguistic behaviour will be a function which yields, for each sentence uttered and whatever its grammatical mood, a corresponding indicative (open or closed) sentence of the language under study. (These second, third 
and fourth components constitute, roughly, what McDowell, following Michael Dummett, calls the 'theory of force' for the linguistic community under study.) Finally, we shall have the theory of sense for the language concerned: staying with agnosticism, this will pair the indicative yield of an application of the fourth component with some indicative sentence in our (the interpreters') language purporting "to give the sense" of the indicative sentence yielded by that fourth component.

Any theory with that structure would place us to redescribe the observed events. All that could originally be said was: 'He emitted the noises...'; but a theory with the structure described will place us to move to descriptions like 'He asserted that $p$ ', 'He asked whether $q$ ', 'He ordered that $r$ '. But nothing yet said tells when such a redescription is a good redescription; nothing yet said tells which of the theories of linguistic behaviour with the structure described is the correct theory to use in redescription. This omission is corrected by consideration of the connections, diverse and complex, between the redescriptions of linguistic actions of speakers which are licensed by theories of linguistic behaviour and the ascriptions of propositional attitudes to those same speakers. Simplifying unduly, if someone asserts that $p$, then, standardly, he believes that $p$; if someone orders that $q$ then, standardly, he desires that $q$; and so on. Thus employment of a particular scheme of redescription of a speaker's actions will license, in admittedly complex ways, ascriptions of propositional attitudes and of expressions of propositional attitudes to that speaker. But such ascriptions can be intelligible or unintelligible in countless ways. It can be no part of rendering an action intelligible to see that action as the expression of some propositional attitude which it is unintelligible that the speaker should have or which it is un- 
intelligible that he should then and there be expressing. A theory of linguistic behaviour is acceptable only if it produces ascriptions to speakers of propositional attitudes and of expressions of propositional attitudes which it is intelligible, in the light of all we know and believe about the speakers concerned, that they should have and produce. To that end-the maximization of intelligibility of propositional attitude ascriptions and propositional attitude expression ascriptions-any part of the theory of linguistic behaviour can be adjusted.

Aside from that general constraint upon the overall theory of linguistic behaviour, all we apparently know about its component theory of sense is that it is to pair designated indicative sentences of the language under study with used sentences of our, the interpreters', language. But now according to McDowell, following Davidson, ${ }^{3}$ we can discover more about that component theory.

Suppose there to be some key concept $f$ in the theory of sense such that the sense of a sentence is given by stating its $f$-conditions, the sense of a word being in central part its repeatable contribution, or contributions, to the f-conditions of those indicative sentences containing that word. ${ }^{4}$ The output of the theory of sense will take the form of

$$
s \text { is } f \text { if and only if } p
$$

for each indicative sentence of the language under study, where $s$ is replaced by a designation of that sentence and $p$ by a sentence of our, the interpreters', language

3 In Davidson's "Truth and Meaning”, Synthese, VII (1967), reprinted in J. W. Davis et al. (eds.), Philosophical Logic (Hingham, Mass., 1969), pp. 1-20. The discovery comes at p. 6.

- See my Wayo of Meaning, Pp. 49-52, and Pp. 23-4 for the rationale for two of the assumptions here. 
which purports to "give the sense" of that sentence. But now, according to McDowell, we should note two further truths. First, the sentence $p$, given the aim of the theory of sense, "can be used to specify the content of propositional acts potentially performed by uttering" the sentence designated (TC, p. 46). And secondly, "appending a truth-predicate to a designation of a sentence produces a sentence apt... for saying... the very thing... which could have been said by using the original sentence" (TC, p. 46). Noting those truths we are led to see, according to McDowell, that "if the lacuna in 's......p' is filled... by... 'is $f$ if and only if', the requirement of interaction with a theory of force ensures that an acceptable theory of sense will remain acceptable if ' $f$ ' is replaced by 'true'" (TC, p. 46). So "truth is what a theory of sense is a theory of", such that "a theory of sense would, as Frege thought, specify truth-conditions for sentences" (TC, p. 47).

3. That argument of McDowell's, like others for this undeniably productive conception of sentence sense, is not unproblematic. But I wish to focus attention, not upon the argument itself, but upon the content of the conclusion drawn. In particular, I want to ask: what claim does McDowell's theory of sense have to being considered a theory of meaning? Behind that particular question is a more general one: in virtue of doing what would a theory be a theory of meaning?

Perhaps those questions are, ultimately, trivial verbal ones. But the claim that such they are could yet be a substantive, non-trivial claim.

In search of substantive answers to the questions, the obvious place to look is the area occupied by the connections between the notions of meaning and understanding. This seems to be McDowell's idea too, since 
he refers to what he calls the "attractive suggestion" of Dummett that the point of the notion of sense "is to capture (in part) a notion of meaning which makes it true that a theory of meaning is a theory of understanding" (PN, p. 165). However, while the place we are to look might be obvious, what is there to be seen does not come so readily to even the open eye. The concept of understanding is one of the most contested in the philosopher's repertoire.

4. Gareth Evans and John McDowell claimed, in their editors' introduction to Truth and Meaning, that natural language use is unreflective: the "character of most ordinary human use of language" is "habitual, unthinking" (EI, p. xx). Our conception of an ordinary speaker's understanding of his natural language will be determined by our, theoreticians', understanding of, and evaluation of, this claim about natural language use.

For the moment I shall present a rough, initial gloss upon "the" phenomenon of the unreflective character of natural language use - a gloss going well beyond anything said by Evans and McDowell. In general, people say things without working out how they are to say them and without reflection upon why they are saying them. In general, others understand what was said without working out what was said, how it was said, or why it was said. One who understands a language is competent in usage of that language: competent both in using that language to say things and in understanding other's usage of that language to say things. But that competence is generally a practical, unreflective competence, a technique. The usual manifestations of that competence are the sayings of things in intelligible, pertinent ways and the pertinent, intelligible responses, both verbal and non-verbal, to the sayings of others. 
Such manifestations are not generally a reflection of thought as to the form, nature or point of the actions so performed.

No veridical account of an ordinary speaker's understanding of his natural language could imply that the commonplace usage of that language which manifests that understanding is reflective, non-habitual or ratiocinative. And that matters for any attempt to account for ordinary speakers' linguistic competence through attribution to such speakers of explicit propositional knowledge of any of the theory of linguistic behaviour which we, as reflective interpreters, construct: any such attribution must be compatible with the fact of the unreflective nature of ordinary linguistic behaviour.

5. Within McDowell's writings it is perhaps possible to detect an argument designed to show that we can indeed defensibly attribute to ordinary speakers propositional knowledge of part of the theory of sense which we reflectively construct. ${ }^{5}$ That part is constituted by the interpretative sentences delivered by the theory of sense, sentences giving the truth-conditions of designated indicative sentences of the language under study.

Any competent speaker of a language has, in virtue of his competence, the ability to understand utterances in that language of those that speak that language (including himself). That ability shows itself in instantiations of a general capacity to report utterances in the language concerned: it shows itself in the ability to say things like 'He said that $p$ ', 'She ordered that $q$ ', and so on. Given this ability, requisite for competence, to produce (correct) reports of sayings which are made by using the language concerned, we can unproblematically

8 See TC, Pp. 54-5 and p. 64.

52 
say the following of any competent speaker: that, in virtue of his competence, he knows, on any particular occasion of intelligible utterance in the language concerned, that the speaker said that $p$, or that the speaker ordered that $q$, and so on.

Concentrating upon reports of assertoric utterances, we might now invoke what might appear to be a harmless gloss upon the notion of saying (or asserting) used in such reports, and so used in our consequent ascriptions of propositional knowledge to speakers, to reconstrue or transcribe those reports and those ascriptions in the following way. First, we take 'He said (asserted) that $p$ ' as tantamount to 'The sentence he (assertorically) uttered is true if and only if $p$ '. Then, instead of atributing to our linguistic competent the knowledge, on any particular occasion of intelligible utterance in the language concerned, that the speaker said that $p$, we attribute to him the knowledge that the sentence the speaker (assertorically) uttered is true if and only if $p$. In this way, the thought might be, we are led to see competence in the reporting of others' sayings or assertings, a necessary condition of understanding, as a manifestation of explicit propositional knowledge of the interpretative sentences yielded by the theory of sense, sentences giving the truth conditions of designated indicative sentences of the language under study.

6. Two of the worries which arise about any such form of argument are acknowledged by McDowell. The first explains the, at points, tortuous phrasing in my presentation of the argument. The propositional knowledge we are invited to attribute to those who understand a language is of a somewhat odd capacitative character. What the competent speaker has is the ability to recognise, on any particular occasion of intelligible utterance, 
that the sentence the speaker (assertorically) uttered is, say, true if and only if $p$. As McDowell has it,

a speaker's understanding of a sentence is represented as consisting, not in actual knowledge of anything, but in the capacity to know on suitable occasions of utterance of the sentence, something which a theoretical description of his capacity would generate by combining, with the deliverances, for those utterances, of the theory of force, that theorem of the theory of sense which specifies what it is for it to be true (TC, p. 55).

McDowell adds, however, that "it seems a harmless abbreviation to say, loosely, that a speaker's understanding of a sentence is represented as knowledge of what it is for it to be true" (TC, p. 55).

That loose abbreviatory way of speaking serves also to brush over a second worry (which I think McDowell recognises). We are searching for some substantive reason for holding that the theory of sense (the theory of truth-conditions) is a theory of meaning. The examination of the notion of understanding and of the matter of what propositional knowledge constitutes (at least in pqrt) the linguistic competent's understanding is presumably motivated by the following thought: that meaning is what is (propositionally) known by one who understands the language. Thus given McDowell's conclusion that one who understands the language knows the deliverances of the theory of sense for that language, we are given some (substantive) reason for holding that theory of sense to be a theory of meaning.

But there is a gap to be filled before the desired conclusion can be drawn. If the capacity to report the sayings of those that speak the language is taken to show (capacitative) knowledge of "the meaning" of what was said, more must be done to establish the desired specific connection with the theory of sense: for nothing yet said directs knowing "the meaning" of sayings to knowledge 
of the deliverances of the theory of sense rather than to knowledge of the combined deliverances of the theories of sense and force. Note, again, McDowell's acceptance of Dummett's idea that the point of the notion of sense is "to capture (in part) a notion of meaning which makes it true that a theory of meaning is a theory of understanding" (PN, p. 165, emphasis mine). And elsewhere McDowell holds that the capacity "to interact with a theory of force, in the appropriate way, would certify a theory as part of a systematic description of such understanding, and hence as part of a theory of meaning" (TC, p. 45, emphasis mine).

Until this gap is filled, it is misleading at best to take McDowell's arguments to establish the truth of "the truth-conditions theory of meaning"; at most we have been given reason to think that a theory of truth will be part of a theory of meaning. If this gap cannot be filled, and if McDowell is right in holding that "meaning cannot be anything but what a theory of meaning for any language is a theory of" and also that "a theory of meaning is a theory of understanding", then we have reason to think that the notion of meaning is a complex, hybrid one resisting encapsulation in any tidy formula.

7. There are further difficulties for the argument which do not, I think, receive acknowledgment in McDowell's writings. One of these other difficulties is of special importance for the central theme of this paper.

Fairly or unfairly, I have represented McDowell as trying to give some non-arbitrary reason for holding the truth-conditional theory of sense to be a theory of meaning. For any such reason to be acceptable it has to be compatible with acknowledgement of the unreflective nature of natural language use. So any such reason which presumes the attribution to ordinary speakers 
of propositional knowledge of any part of the theory of linguistic behaviour which we, as theorists, have reflectively constructed ought not in any way to deny, in virtue of the presumed knowledge attribution, the general unreflectiveness of the exercise of the linguistic competence of those speakers. So I take the thought behind the form of argument here attributed to McDowell to be that such denial is avoided, such falsification of the phenomenology of language use is absent, if the knowledge attributions made to ordinary speakers receive specific manifestations within their commonplace linguistic behaviour. Such specific outer manifestations eliminate any need falsifyingly to tamper with the inner phenomenology in order to create some grounding for the corresponding knowledge attributions. Hence the emphasis placed within the argument upon manifestations of the ability correctly to report the sayings of other speakers of the language: such manifestations are seen as amounting to specific manifestations of the knowledge attributed to speakers.

But if that representation of the argumentative strategy is correct, yet another lacuna remains to be filled. In his commonplace reporting ability the competent speaker shows only knowledge of the deliverances of the combined theories of sense and force; he does not thereby yet show knowledge of the component deliverances of the theory of sense which we, as reflective interpreters, have distinguished as part of our generation of the deliverances of the combined theories of sense and force. In order to take the deliverances of the theory of sense to be known by ordinary competent speakers, it seems, on the present representation (or misrepresentation) of McDowell's strategy, that such knowledge attributions must receive some specific manifestations in the behaviour of those speakers. But nothing has 
yet been said as to how the competent speaker might manifest his knowledge of the deliverances of the theory of sense rather than merely his knowledge of the combined outputs of that theory in interaction with the theory of force. This is not the senseless request for some specification of ways in which speakers might manifest their knowledge of deliverances of the theory of sense in independence of all their other knowledge and propositional attitudes. Rather, to repeat, the request is just for some specification of ways speakers might make manifest their knowledge of those deliverances as opposed merely to knowledge of the complete descriptions of linguistic actions - the descriptions which we, as reflective theorists, have admittedly obtained through combining those deliverances of the theory of sense with the yields of the theory of force.

If meaning is that which is known in virtue of understanding, then until that gap has been filled we shall have no clear reason for holding that truth-conditions are even part of meaning. For, until that gap is filled, we shall have no reason to hold that the content of a comprehending speaker's knowledge is structured for that speaker in the way that we, as theorists, might see it as being. What the comprehending speaker knows can be seen by us as that which is yielded by the combined, but distinct, theories of sense and force; but that does not imply the speaker too to know both the deliverances of the theory of sense and the outputs of the theory of force.

8. Up to this point it has been granted that speakers do at least know the combined deliverances of the theories of sense and force. But now even that concession must be questioned.

At least usually, an ordinary speaker's ability to re- 
port sayings does not reveal an ability to report the literal content of sentences (assertorically) uttered. Such reports do not usually give the literal sense, the literal truth-conditions, of the sentences uttered. Rather, they purport to capture the gist, the conversational import, of the sayings.

Knowledge of speech is not (yet) knowledge of language; for knowledge of gist is not (yet) knowledge of the truth-conditions of sentences uttered. Indeed, most conversational exchange reveals no explicit awareness even of the particular sentences uttered. ${ }^{6}$ We can rarely say which these sentences were, even immediately after hearing, or uttering, them. Awareness of particular sentences uttered is rarely to the point, rarely to the point of the conversational exchange. Which serves to make it unsurprising that conversation can function perfectly well even in the (far from rare) cases in which the majority of the "sentences" uttered are either incomplete or ungrammatical by the lights of our (interpreters') theory of the language.

The unreflectiveness of natural language use thus cuts deeper than was perhaps initially suspected. The competent speaker does not work out what was said, not just in that, say, he does not work out the literal sense of sentences uttered by reference to their semantic structures and the semantic contributions of their components, but also, more radically, in that he does not work out what was said-the gist, the conversational import of an utterance-by reference to the literal sense of the sentence uttered together with other contextual factors.

If all that is so, an ordinary speaker's ability to report sayings usually manifests no propositional knowl-

\footnotetext{
- Sometimes there need, strikingly, be no awareness revealed-mor even had-of which language was employed (think of conversations between bilingual speakers).
} 
edge of even the combined outputs of the theories of sense and force. Our argument for the defensibility of the attribution to speakers of knowledge of the deliverances of the theory of sense reached at one point the thought that we can defensibly attribute to one who understands a language the (capacitative) knowledge, that, say, the sentence another (assertorically) uttered was true if and only if $p$. But even though the sentence the other uttered was in fact, say, the sentence $s$, we cannot proceed unproblematically to substitute coreferential expressions so as to obtain the conclusion that the speaker knows (capacitatively) that $s$ was true if and only if $p$. If awareness of sentence uttered is at best unusual (because not to the point), activation of any capacitative knowledge of the deliverances of the theory of truth for designations of the sentences uttered will be at least as unusual. But the present worry about our argument does not rest upon that, perhaps slight, logical point. It is a worry which can be eased, as a first step, only by the discovery of reasons for holding that the unreflective competent speaker has knowledge even of the combined deliverances of the interpreters' theories of sense and force.

9. The conception of the unreflective nature of natural language use had by Evans and $\mathrm{McD}$ Dowell appears to have been somewhat different from that which we have just been led to. They began, as did I, from "the habitual, unthinking character of most ordinary human use of language" (EI, p. xx). They elaborated upon that characterization while examining a neo-Gricean theory of meaning. In that context, they came to the following conclusion:

If we take seriously the unreflectiveness of ordinary linguistic behaviour, we shall be inclined to return to seeing $X$ 's behaviour 
[his comprehending response to an utterance of sentence $S$ by person $Y$ at time $t$ ], in normal cases at least, as the resultant of just the two factors: $X$ 's belief about what $S$ means on $Y$ 's lips at $t$, and $X$ 's beliefs about the facts of the appropriate matter (EI, p. xxi).

More generally their conclusion was that "it is essential to language as we know it that our understanding of meanings should normally be perception of meanings, and hence precisely not a matter of inference" (EI, p. $x x i$ ).

With the rejection of the neo-Gricean theory I have no quarrel. But for the positive claims made by Evans and McDowell, I should require (more) argument. Just what shows that in "normal cases" the comprehending $X$ has any beliefs about what the sentence $S$ means on $Y$ 's lips at $t$, or means period? What shows that the "meaning" that is 'perceived', not 'inferred', is the literal sense of the sentence $S$, or its literal sense on $Y$ 's lips at $t$, and not, rather, what was meant in the context, the conversational import of the saying? Why is it wrong to hold that recognition of conversational meaning, of import, is itself "precisely not a matter of inference"? If the phenomenology of language use is to guide us, then it is important to get the description of that phenomenology right.

10. I have extracted from McDowell's writings an argument which I have taken as being designed to show that the theory of sense, the theory of truth-conditions, is indeed a theory of meaning. That there are lacunae in that argument so taken I presume now to have been shown. It has not yet been shown that there is no acceptable way in which these lacunae can be eliminated or side-stepped. That would of course be an endless task. But it is especially instructive to consider how 
one natural way of responding to my criticisms of the argument is blocked to one who accepts certain other views which, undeniably, are subscribed to by McDowell himself.

The line of response concerned seeks to establish that the linguistic competent's capacity to report the gist of sayings would be inexplicable were it not grounded upon that same competent's ability to recognise the literal sense of sentences uttered in those sayings. The literal sense of an uttered sentence can be seen by the reflective interpreter to combine with contextual factors so as to determine the conversational import of the saying. Now, a competent native speaker can recognise, and report correctly, the conversational import of an indefinitely large number of novel sayings in widely varying contexts. That capacity, it is claimed, would be unacceptably mysterious were it not grounded upon the competent speaker's ability to recognise on each occasion of intelligible use of his language both the literal sense of the sentence uttered and the relevant contextual considerations. On pain of unintelligibility such a competent speaker must therefore mirror, however dimly, the reflective interpreter's appreciation of the determination of conversational import.

Such a line of thought is scarcely available, as it stands, to McDowell. On such a line, implicit propositional knowledge is attributed to speakers for the purposes of explanation of their linguistic performances and capacities. Yet McDowell himself has frequently railed against the philosophical sins inherent in any such approach to the understanding of linguistic behaviour.

He tells us:

Comprehension of speech in a familiar language is a matter of unreflective perception, not the bringing to bear of a theory... Certainly, it may be said, understanding a language does not 
consist in explicit knowledge of a theory. But we are not precluded, by that concession, from saying... that understanding a language consists in implicit knowledge of a theory... The attraction of the notion of implicit knowledge, one might suppose, lies in its promise to permit us... to explain exercises of the capacity involved, in terms of a postulated inner mechanism (PN, Pp. 147-8).

But it is clear that for McDowell the attraction is as spurious as the promise. He approvingly quotes a remark of Dummett's which denies "that the notion of sense is to be thought of as employed in the construction of purportedly explanatory mechanisms". 7 As McDowell puts it, the purpose of psychological explanations of behaviour within his conception of a theory of language "is to confirm the descriptive adequacy of a theory, not to put an explanatory mechanism through its paces" (PN, p. 148). For McDowell, the theory serves to redescribe the actions of speakers such that it is intelligible that the actions were intentional under those descriptions; and that is held to be utterly different from pursuit of explanation of how other competent speaker's "arrive at knowledge of what others are doing, under those descriptions" (PN, p. 149) or of explanation of how speakers "contrive to embody actions which are intentional under those descriptions in their own verbal behaviour" ( $\mathrm{PN}$, p. 149). McDowell's presuppositions in these passages as to quite what the objects of unreflective perception are in the comprehension of speech and as to under quite which descriptions the actions of speakers are intentional have already been subjected to doubt

7 PN, p. 148. Dummett's remark was this: "A model of sense is not a description of some hypothesised psychological mechanism... A model for the sense of a word of some particular kind does not seek to explain how we are able to use the word as we do: it simply forms part of an extended description of what that use consists in." (Frege: Philosophy of Language (London, 1973), p. 681.) 
here ( $\S \S 8-9)$. The point now is simply that one natural line of response to those doubts, that outlined at the beginning of this section, exemplifies precisely the general strategy of argument which McDowell in these same passages so emphatically rejects.

Whether that point has a force beyond the merely ad hominem depends upon the strength of McDowell's grounds for his rejection of that strategy. Any attribution to speakers of implicit propositional knowledge for purposes of explaining their verbal behaviour will, he claims, introduce "the psychologism which Frege detested", which detestation "is well placed" (PN, p. 148). That dismissal is elaborated thus:

There is no merit in a conception of the mind which permits us to speculate about its states, conceived as states of a hypothesised mechanism, with a breezy lack of concern for facts about explicit awareness. Postulation of implicit knowledge for such allegedly explanatory purposes sheds not scientific light but philosophical darkness... Hypothesised mech anisms are not the way to save from behaviourist attack the indispensable thought that all is not dark within. We get no authentic and satisfying conception of the mind from either of these philistine extremes (PN, pp. 148-9).

Phew! $!^{8}$ But let me anyway make a few, tentative remarks which may connect with the point beneath the passion.

Earlier, I criticised any invention of phenomenological presences made in order to ground knowledge attributions to speakers ( $\S 7)$. What is now at issue is the initially distinct manoeuvre of attributing knowledge to speakers, such attributions being purportedly grounded in their explanatory potential, in complete disregard of

- ${ }^{\alpha}(A) n$ exclamation of petty vexation, unexpected difficulty, impatience, relief, contempt, etc. [A half-formed whistle.]" (Chambers Trentieth Century Dittionary (Edinburgh, 1972).) 
the lack of any appropriate phenomenology. If this manoeuvre avoids the error of the earlier one-if, that is, this new manoeuvre does not slide into phenomenological invention-then it does so only to incur a distinct difficulty. In a slightly different context I once put the difficulty thus:

The only reason we have for adopting the proffered cognitive claims, the only route we have to their truth, is their utility in providing the required explanation. The postulated cognitive states have no other consequences than the restricted range of facts they purport to explain - except, perhaps, a bogus psychologism and a false optimism about the ease of assessing a semantic proposal. Such an explanation is no explanation at all. 9

The point being groped for there with the reference to "the restricted range of facts" was later beautifully spelt out, and its consequences articulated, by Gareth Evans in a passage well worth quoting in full.

Possession of tacit [i.e. implicit] knowledge is exclusively manifested in speaking and understanding a language; the information is not even potentially at the service of any other project of the agent, nor can it interact with any other beliefs of the agent (whether genuine beliefs or other tacit 'beliefs') to yield further beliefs. Such concepts as we use in specifying it are not concepts we need to suppose the subject to possess, for the state is inferentially isolated from the rest of the subject's thoughts and beliefs. There is thus no question of regarding the information being brought by the subject to bear upon speech and interpretation in rational processes of thought, or of making sense of the subject's continued possession of the information despite incorrect performance, due to his 'not thinking' of the rule at the appropriate time, etc. ${ }^{10}$

The explanatory thinness of the proposed employment

- Waye of Meaning, p. 234.

10 "Semantic Theory and Tacit Knowledge" in Steven H. Holtsman and Christopher M. Leich (eds.), Wittgenstein: to Follow a Rule (London, 1981), at pp. 133-4. 
of the hypothetico-deductive model is clear; only a slide into phenomenological invention could have hidden that from us. That thinness corresponds to the at best attenuated sense in which the hypothesised explanatory mechanisms are cognitive, rather than, say, merely physical, states. My only, perhaps slight, disagreement with Evans' position in the paper from which that passage is taken is that it seems to presume there still to be something to be said for continued employment of, admittedly attenuated, cognitive talk. Perhaps there is, but it has not yet been said. ${ }^{11}$

The reflective interpreter can ascend to recognition of the conversational import of ordinary speaker's sayings from his recognition of the literal truth-conditions of the sentences they utter together with his due sensitivity to the morass of contextual considerations. That ascent of the theorist might build upon an earlier ascent of his through which he arrives at recognition of the literal truth-conditions of sentences uttered from consideration of the truth-bearing import of the words, phrases and sentential structures occurring in those sentences. But such a two-part ascent of the theorist does not rehearse some implicit ascent by ordinary speakers. Those speakers begin from the point at which the theorist laboriously arrives. For those speakers to recover the theorist's route may be as laborious for them as was the reverse journey for the theorist.

A child is taught to speak and to understand the speech of others. If we persist in saying that thereby

11 I take McDowell to believe something stronger: that if anything were to be said, it would of necessity involve a conception of the mind that was neither authentic nor satisfying. I would like to think that some of my comments in "Conscious Mind and Unconscious Inference" (Crítica, 34, XII (1980), pp. 91-101), a discussion of Hugo Margáin's Racionalidad, lenguaje y filosofia, bear (favourably) upon that stronger claim. 
he "learns a language" we have to beware of thinking that such "learning" is correctly modelled upon that of an adult speaker learning a second language; it could not be. ${ }^{12}$ In being brought to speak, the child has brought within his immediate perceptual grasp a new world of facts. Those are facts about conversational meaning, about gist, not facts about the literal truthconditions of indicative sentences. In being brought to understanding, the child is enabled to recognise directly, non-inferentially, what is conversationally meant within verbal exchange taking place within a certain linguistic community; no theory is brought to bear in his exercise of that understanding. The only "explanation" needed of his "mysterious" perceptual ability is that which refers to the public practices and procedures which issued in that ability.

11. If meaning is that which is known in virtue of understanding, that which must be known by any competent speaker, then the conclusion invited by the foregoing is that meaning is nothing but conversational meaning, gist. Further, it seems that from the standpoint of speaker's understanding, there is no theory of conversational meaning, of what is meant. So there is nothing for a theory of meaning to be a theory of.

Those conclusions are invited at best. Perhaps quite distinct arguments designed to show that a theory of truth-conditions for a language is a theory of meaning for that language can be adduced and defended (we may have been searching in the wrong place all along). Or perhaps there are other putative "theories of meaning" which are resistant to the worries of this paper. I no more think of myself as having eliminated here those op-

12 Cp. Ludwig Wittgenstein, Philosophical Investigations (Oxford, 1953), \$32. 
tions than I would wish what has been said here to give sustenance to contemporary intellectual Luddites. ${ }^{13}$ It is a good question what would be the philosophical consequences of it proving that those options are closed to us.

That we should abandon talk of the theory of meaning, talking instead of the theory of linguistic behaviour and of its components designated by terms of art is a thought that will not perhaps disturb many at the outset. But less of a ground for complacent acquiescence is the fact that that thought is in large part prompted by our utter unclarity as to the connections between the components and deliverances of the theory of linguistic behaviour and competent speakers' propositional knowledge. Philosophers' use of language can be as unreflective as that of other mortals. Like many, I have been prone to characterising my efforts at articulating a theory of linguistic behaviour in terms of seeking to secure a "propositional representation" of a "practical capacity". I now fear that I did not, and do not, know what I was saying when I said that. 